УДК 352/354-1; 332-02

Уткова М.A.

ФГБОУ ВО «Мурманский арктический государственный университет», Мурманск, e-mail: mtim76@mail.ru

\title{
ПРОЕКТНОЕ УПРАВЛЕНИЕ В СИСТЕМЕ УСТОЙЧИВОГО РАЗВИТИЯ ЭКОНОМИКИ РЕГИОНА
}

Ключевые слова: управление проектами, устойчивое развитие, регион, эколого-экономическая безопасность, экономика, образовательная среда, Арктическая зона, Мурманская область.

Статья посвящена проблеме взаимовлияния устойчивого развития и инновационного проектного управления в системе взаимодействия субъектов экономики и образовательной среды региона. Работа выполнена по основной специальности 08.00.05 - Экономика и управление народным хозяйством (по отраслям и сферам деятельности). В работе определена роль проектного управления в РФ в решении задач предстоящего десятилетия, выделены особые условия социально-экономического развития Арктической зоны РФ, компоненты, способы, механизмы устойчивого развития экономики региона, проблемы взаимовлияния устойчивости и инновационности, обоснованы ключевые подходы внедрения проектного управления применительно к условиям устойчивого развития экономики и образовательной среды региона, с представлением результатов проектной деятельности, осуществляемой в условиях реформы образовательной среды в Мурманской области в период с 2013 по 2019 гг. В целом материалы исследования позволяют выделить в системе эколого-экономической безопасности регионального управления ключевые факторы развития образовательной среды Арктического региона в условиях инвариантного сочетания устойчивости и инновационности.

Utkova M.A.

Murmansk Arctic State University, Murmansk, e-mail: mtim76@mail.ru

\section{PROJECT MANAGEMENT IN THE SUSTAINABLE ECONOMIC DEVELOPMENT OF THE REGION}

Keywords: project management, sustainable development, region, ecological and economic safety, economy, educational environment, Arctic zone, Murmansk region.

The article is devoted to the problem of interaction between sustainable development and innovative project management in the system of interaction of economic entities and the educational environment of the region. The work was performed in the main specialty 08.00.05 - Economics and management of the national economy (by industry and fields of activity). We determined the role of project management in the Russian Federation in solving the problems of the coming decade, highlighted the special conditions of socio-economic development of the Arctic zone of the Russian Federation, components, methods and mechanisms of sustainable economic development of the region, the problems of the interaction of sustainability and innovation. In justified as the key approaches in the implementation of project management as applied to sustainable development of the economy and the educational environment of the region, with the presentation of the results of the project activities in the context of the reform of the educational environment in the Murmansk region in the period from 2013-2019. In General, the materials of research allow to allocate in the system of ecological and economic safety of the regional management of the key factors in the development of the educational environment of the Arctic region in terms of invariant combinations of sustainability and innovation.

\section{Введение}

Задачами на предстоящее десятилетие, в послании Президента РФ В.В. Путина от 01.03.18 г. обозначены обеспечение уверенного долгосрочного роста реальных доходов граждан, обновление структуры занятости, обеспечение людей современным высокооплачиваемым и рабочими местами. Экономика устойчивого развития региона на сегодняшний день претерпевает ряд изменений, с одной стороны, способствующих сбалансированному развитию ресурсной базы, а с другой, вызывающих нехватку дополнительных возможностей, в силу недостаточности охвата среды взаимодействия субъектов. Все обозначенные вопросы будут решаться в обозначенный период с помощью механизмов проектного управления (путем определения реальных проблем, выявления ключевых партнеров, формулировки целей и определения четких сроков исполнения). 
Вместе с тем, здесь следует подчеркнуть, что Арктическая зона РФ, являясь особой зоной с особыми условиями социально-экономического развития, включает Мурманскую область, Ненецкий, Чукотский и Ямало-Ненецкий автономные округа, муниципальное образование городской округ «Воркута» (Республика Коми), ряд муниципальных образований Архангельской области (в том числе муниципальное образование «город Архангельск»), несколько районов Красноярского края (Таймырский Долгано-Ненецкий муниципальный район, Туруханский район, городской округ город Норильск), северные улусы Республики Саха (Якутия), а также некоторые земли и острова Северного Ледовитого океана. При этом город Мурманск, являющийся крупнейшим портовым центром Мурманской области, находящийся за Полярным кругом, определяет Кольскую опорную зону. Здесь создана инфраструктура для обслуживания перспективных проектов добычи углеводородов на шельфе арктических морей, создаются базы для обеспечения разведывательных и буровых работ на шельфе Баренцева, Карского и Печорского морей, реализуется проект верфи по строительству крупнотоннажных платформ, планируемых к задействованию в проекте «Арктик СПГ-2» в Ямало-Ненецком автономном округе (ЯНАО), а самым крупным проектом на территории стал Мурманский транспортный узел (МТУ) на западном берегу Кольского залива. Так, ЯНАО называют «воротами в Арктику», а Мурманск - «форпостом России в Арктике».

Сегодня инновационный мир делает прорыв во всех областях экономики и управления. Проектное управление перемещается в практику повседневной жизни, превращаясь в инновационное проектное управление, а в условиях региона, особой Арктической зоны, также обостряются взаимовлияния устойчивости и инновационности.

Цель исследования: обоснование ключевых подходов внедрения проектного управления применительно к условиям и факторам устойчивого развития экономики и образовательной среды региона, с акцентом на эколого-экономическую безопасность является основной целью проводимого исследования.

\section{Материал и методы исследования}

В качестве методологии исследования выступает системный подход к обозначенной проблеме внедрения механизмов проектного управления применительно к системе устойчивого развития экономики и образовательной среды региона. В качестве материалов исследования применены результаты проектной деятельности, осуществляемой в условиях реформы образовательной среды в Мурманской области в период с 2013-2019 гг. Методами исследования выступили качественный и количественный анализ, статистическая обработка информации, сравнение, классификация, обобщение.

\section{Результаты исследования и их обсуждение}

В ходе проведения исследования в период с 2013 по 2019 гг., автор подтвердил необходимость активизации участия субъектов образовательной среды в разнообразной проектной деятельности, проводимой в политике опорного ВУЗа, от которой сегодня зависит развитие региона, муниципалитетов, образовательной политики в обозначенном стратегическом русле развития Арктической зоны РФ. Ведь, несомненно, образовательная среда - это среда, формирующая устойчивость и возможности инновационного проектного развития субъектов, в ней создаются компоненты, способы, механизмы устойчивости, она обладает неиссякаемыми возможностями развития проектной деятельности, в силу постоянного взаимообмена информацией, знаниями, умениями и навыками между субъектами среды. Недавние исследования показали, что ключевые элементы инновационности развития зависят еще и от сферы деятельности: ученому полезнее всего умение думать и рассуждать и стремление к истине; в искусстве более важно стремление к красоте, фантазия, живое воображение; бизнесмен полагается на эмоциональный интеллект и экстравертность, потому что инновации в значительной степени зависят от способности продать кому-то свою идею. Но при этом неотъемлемой частью образовательной среды является инновационность, как возможность быстрой реакции на происходя- 
щие реформы и перемены, а сегодняшние высокоскоростные изменения предполагают эффективное взаимодействие субъектов образовательной, социальной среды, бизнеса и государства.

В составе реализации приоритетных проектов в образовательной среде обозначен девятый проект «Повышение конкурентоспособности российского высшего образования», в составе которого уже известные проекты: «Вузы как центры пространства создания инноваций», «Современная цифровая образовательная среда в Российской Федерации», «Экспорт российского образования». Конечно, реализация проектного управления в условиях взаимодополнения субъектов деятельности играет достаточно положительную роль в активизации деятельности в среде и способствует ускорению развития общественно полезных решений, однако не все так просто, как может показаться на первый взгляд.

Способности инновационной среды образовательных организаций в адаптации к изменившейся ситуации и обеспечении динамического равновесия отличаются следующими признаками: - стабильностью, способствующей достижению текущих задач; - восприимчивостью и способностью к нововведениям; - необходимым временем для обеспечения надлежащего изменения в целях и средствах; - адаптивностью для соответствующей реакции на внешние и внутренние возможности и требования образовательной среды. Здесь эколого-экономическую безопасность развития региона можно трактовать как процесс постоянного сохранения динамики и равновесия путем целенаправленного использования ресурсного потенциала и условий внешнего обитания. Ресурсно-продуктивный подход объединяет в себе оценки природного, экономического и сервисного потенциала, что в дальнейшем позволит сформировать интегральный показатель социального и экономического капитала территорий. Вот тут-то и таится скрытый смысл данного явления взаимодополнения инновационности и устойчивости. Для реализации пусть даже самой смелой и отличной идеи, необходимы ресурсы, и не только человеческие и, разумеется, финансовые, но и производственные, материальные, духовные, интеллектуальные и т.д. А поиск этих ресурсов в условиях Арктической зоны становится все более и более затруднительным, ввиду ежегодного оттока населения, переориентации молодежи на сегодняшние молниеносные впечатления и лиц старшего поколения на поиск возможностей для существования в среде в ущерб завтрашнему инновационному развитию.

Цель инновационного проектного управления, по словам А. И. Добросоцкого [1], - приоретизировать деятельность науки, госорганов, региональных органов власти, социального сектора, бизнеса и общественности для ускоренного реализации крупных современных инновационных проектов с высокой добавленной стоимостью и производительностью труда, способствующей росту высокооплачиваемых специалистов в реальной экономике, формирующих внутренний спрос и сокращающий российский феномен «работающей бедности»; оптимизировать на базе новейших технологий управленческие, инвестиционные и иные издержки с сокращением сроком ввода объектов в эксплуатацию при полной реализации целей проекта.

Управление проектами на государственном уровне доказало свою эффективность в таких странах, как Япония, Великобритания, США. В части российского опыта использования системы управления проектами в государственном управлении можно отметить работу исследователей Д.Г. Красильникова и М.Н. Якимовой, выделивших три основных этапа применения проектного государственного управления: «знакомство» с проектным менеджментом (20052008 гг.); рост количества проектов, с частичным применением профессиональной методологии проектного управления (2009-2012 гг.); рост интереса к развитию «мегапроектов» и начало развития проектной профессиональной методологии (2012-2016 гг.). Выход Постановления Правительства № 1050 от 15.10.16 г. можно считать началом четвертого, нового этапа развития проектного управления в органах госвласти. Среди объектов проекты 11 приоритетных направлений: «Здравоохранение», «Образование», «Ипотека и арендное жилье», «ЖКХ и городская среда», «Международная коопе- 
рация и экспорт», «Производительность труда», «Малый бизнес и поддержка индивидуальной предпринимательской инициативы», «Реформа контрольной и надзорной деятельности», «Безопасные и качественные дороги», «Моногорода и «Экология». В силу того, что в разных регионах проектное управление развивается неравномерно, разным регионам присущи разные «уровни зрелости».

Автором-исследователем Л.А. Раменской [2] представлена типология регионов по опыту развития проектного управления в РФ. Так, пилотные площадки внедрения проектного управления были разделены на 3 уровня: 1 уровень - регионы, имеющие успешные практики внедрения проектного управления; 2 уровень - регионы, имеющие опыт внедрения элементов проектного управления и квалифицированный в отношении методологии профессионального проектного управления персонал; 3 уровень - регионы - последователи. К площадкам первого уровня в сегодняшней управленческой практике отнесены Белгородская область, Пермский край, Ярославская область, Томская, Пензенская, Ульяновская и Волгоградская области. К регионам-лидерам проектного управления можно отнести Белгородскую область и Пермский край. Они уделяют пристальное внимание управлению персоналом, участвующему в проектной деятельности, информационным системам и совершенствованию систем управления проектами. К регионам с высоким уровнем разви- тия проектного управления, имеющим успешный опыт развития отдельных его элементов, отнесены Ханты-Мансийский автономный округ (Югра, Приморский край) и Тульская область. К регионам 3-го уровня относится большинство регионов, которые развивают проектное управление в соответствии с установленными на уровне РФ принципами. Одним из таких регионов является Мурманская область.

Так, на примере Приморского края, при анализе проведенной успешной практики проектного управления, были выделены 5 элементов проектного управления «легализации и успешности», представленные на рисунке 1. К ним были отнесены: 1) понятийный аппарат, оргструктура и инструменты проектного управления; 2) обучение, оценка компетенций, проектный грейд служащего; 3) информационная, аналитическая, методическая поддержка проектов; 4) проектное премирование, нематериальная мотивация; 5) календарно-сетевое планирование, единый архив документации, планирование и контроль освоения. В Приморском крае реализовано около двадцати комплексных проектов [3].

Следует подчеркнуть, что с 2018 года в РФ был введен Национальный рейтинг оценки индексной проектной деятельности, включающий 95 направлений, 23 процесса, более 200 критериев в диапазоне от 0 до 5 баллов (в начальной оценке рейтинг ограничен 3 баллами в связи с начальным этапом развития проектного управления) (рисунок 2) [4].

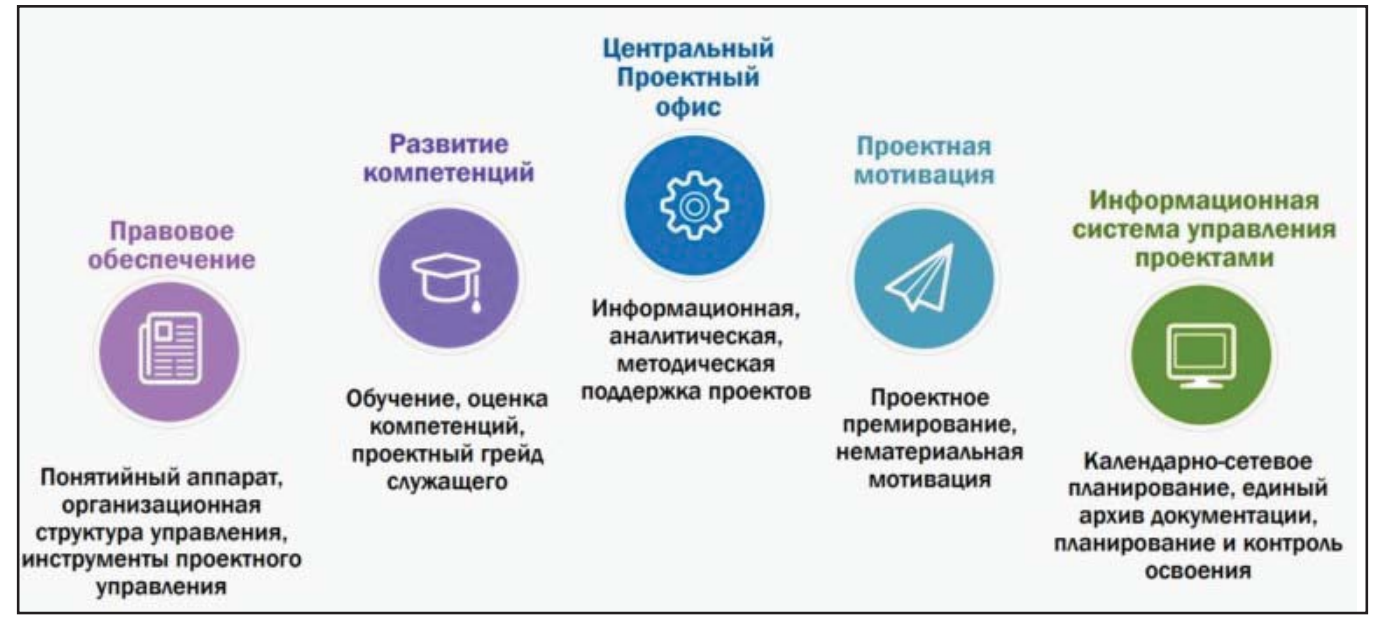

Рис. 1. Элементы проектного управления [3] 


\section{Формула Индекса ориентирована на оценку практических результатов, а не наличие регламентов}
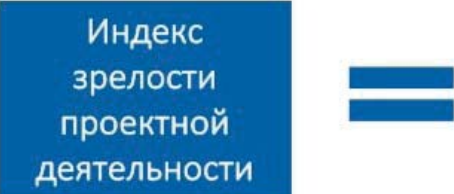
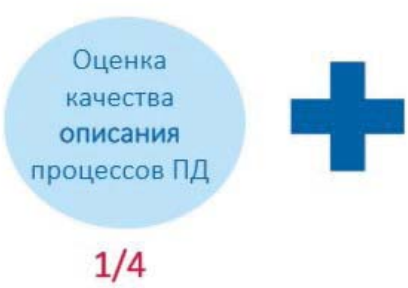

Оценка

качества практического применения процессов ПД

\section{$3 / 4$}

$$
\begin{aligned}
& \text { ИЗ Пдоив }=\frac{\sum_{i=1}^{5} И 3_{Э i}}{5} \\
& \text { ИЗ } 3_{Э}=\sum_{i=1}^{n}\left(\frac{1}{4} O_{\text {OnIi }} / n+\frac{3}{4} O_{\Pi p \Pi i} / n\right) \\
& O_{\text {OnI }}=\left(\sum_{i=1}^{m} O_{\text {OnחII }}\right) / m
\end{aligned}
$$$$
\text { ИЗ пдоив - индекс зрелости ПД ОИВ }
$$$$
\text { ИЗ }
$$$$
O_{\text {Oпппा }} \text { - Оценка качества описания i-гопод-процесса }
$$

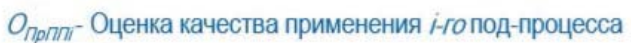$$
\mathrm{O}_{\text {опा }} \text { - Оценка качества описания i-roпроцесса }
$$

$O_{\text {прпा }}$ Оценка качества применения i-гопроцесса

$n$ - количество процессов в элементе СУПД

Рис. 2. Формула расчета индекса проектной деятельности [4]

В пилотной оценке в 2018 году участвовали 15 федеральных министерств и 16 региональных правительств.

В сентябре 2018 года в рамках Московского финансового форума состоялась панельная дискуссия на тему «Проектный подход в государственном управлении: опыт, проблематика, перспективы», в рамках которой были рассмотрены успешные практики проектного управления, на государственном и региональном уровнях, вопросы, связанные с интеграцией проектов в государственные программы, другие актуальные для проектного управления темы, также можно было задать интересующие вопросы экспертам [5].

Полноценное включение регионов и муниципалитетов в проектную работу - одна из ключевых задач, поставленных перед органами власти регионов на федеральном уровне и озвученных департаментом проектной деятельности Аппарата Правительства РФ в октябре 2018 года во время итоговой конференции с координаторами проектной деятельности и руководителями региональных проектных офисов.

Так, в 2017 году в регионе были созданы необходимые условия, разработа- на нормативно-правовая база реализации проектного управления, сформирован Совет по проектной деятельности, создан региональный проектный офис, проведено обучение гражданских служащих и запущены 2 региональных проекта - «Мастер-план развития Териберки» и «Детский технопарк Кванториум» (открылся в 2018 году, 300 ребят занимаются по 11 программам) [7]. В ноябре 2018 года подобная проведенной в сентябре 2018 года на уровне РФ панельная дискуссия была проведена в Министерстве экономического развития Мурманской области [6] (координаторе проектной деятельности и органе власти, исполняющем функции Проектного офиса), где представителем от государственного сектора стал И.В. Винокуров, начальник Управления проектного менеджмента в государственном секторе Аналитического Центра при Правительстве РФ. Участники дискуссии обсудили вопросы внедрения новых управленческих подходов и развития проектной культуры, формирования команд, управления сроками проектов и другие составляющие проектной деятельности.

На 2019-2020 гг. в регионе запланировано тиражирование «Кванториума» 
c градообразующими предприятиями Ковдорского района и г. Кировска Мурманской области, а также вовлечение в практику проектного управления муниципалитетов в составе региона. Распоряжением Правительства Мурманской области от 23.01.19 г. № 11-РП сформирован реестр проектов Мурманской области (МО) по 10 направлениям национальных проектов (НП) в составе 46 реализуемых проектов на территории региона, а также 7 региональным проектам (РП), по которым представлены паспорта и сводные планы [6]. На наш взгляд, представленные в данном Реестре проектов Мурманской области направления проектного управления, в контексте оценки реализации системы устойчивого развития территории региона, можно условно разделить на 3 основные группы: 1 группа - экономические (2 проекта НП «Безопасные и качественные автомобильные дороги», 3 проекта НП «Цифровая экономика», 5 проектов НП «Малое и среднее предпринимательство и поддержка индивидуальной предпринимательской инициативы, 4 проекта НП «Международная кооперация и экспорт», РП «Мастер-план развития с.п. Териберка Кольского района («Мастер план Териберки»); РП «Создание системы обеспечения вызова экстренных оперативных служб по единому номеру «112» на территории Мурманской области («Система-112»); 2 группа - социальные (5 проектов направления НП «Демография», 7 проектов направления НП «Здравоохранение», 8 проектов направления НП «Образование», 3 проекта направления НП «Жилье и городская среда», 3 проекта НП «Культура», РП «Создание детского технопарка «Кванториум» («Кванториум»), РП «Внедрение в деятельность медицинских организаций, оказывающих первичную медико-санитарную помощь, принципов бережливого производства» («Новая поликлиника»), РП «Создание эффективной системы оказания паллиативной медицинской помощи на территории региона», («Паллиативная помощь»), РП «Создание единого органа по управлению гражданской службой и реализации кадровой политики в Мурманской области («Единая кадровая служба»); 3 группа - экологические (6 проектов
НП «Экология» и РП «Реформа системы обращения с твердыми коммунальными отходами на территории Мурманской области («Реформа ТКО»).

Данное разделение, несмотря на условность, подтверждает факт реализации системы устойчивого развития как совокупности экономических, социальных и экологических факторов на территории Мурманской области. Тем не менее, на территории региона реализуется Закон МО от 08.04.2014 № 1723-01-3МО «О государственной поддержке инновационной деятельности на территории Мурманской области и о внесении изменений в отдельные законодательные акты Мурманской области». Во главе инновационной инфраструктуры стоит Министерство промышленности и предпринимательства МO, а в ее составе, согласно данным, представленным на официальном сайте Министерства, находятся ГОУ «Мурманский региональный бизнесинкубатор», Региональное представительство Фонда содействию развитию малых форм предприятий в научно-технической сфере в МО, Некоммерческая микрофинансовая организация «Фонд развития малого предпринимательства в МО» («ФОРМАП»), Мурманский центр научно-технической информации («ЦНТИ») - филиал ФГБУ «РЭА» Минэнерго России, Инновационно-технологический центр Мурманского государственного технического университета. И этот факт может определить еще один вид реализации проектной среды - технологические условия системы устойчивого развития.

Результатами многих проводимых исследований в РФ и за рубежом доказано, что существует тесная взаимосвязь между инновационным развитием субъекта и управлением проектами, инновационное развитие наиболее эффективно происходит именно за счет проектного управления, формируется максимально положительный эффект при осуществлении инноваций при помощи технологий и методов проектного управления [8].

В подтверждение факта выхода Мурманской области на инновационный путь развития говорят следующие данные: ««Инвестиционный кейс» но- 
вой редакции Стратегии социальноэкономического развития Мурманской области составляет 140 проектов стоимостью почти 950 млрд рублей с созданием более 24 тысяч новых рабочих мест. Подготовка новой редакции Стратегии развития региона до 2025 года завершена. Об этом сообщила губернатор Марина Ковтун на пленарном заседании Мурманской международной деловой недели» [9].

При оценке влияния степени «комплементарности устойчивости и инновационности» (термин представлен исследователями Н.С. Васиным, К.С. Рябых как положительная взаимосвязь развития субъектно-объектной среды [10]) Арктического региона, можно определить наличие ключевых факторов, связанных, прежде всего, с уровнем и эффективностью внедрения инноваций в определенных условиях.

В соответствии с Положением об организации проектной деятельности в исполнительных органах государственной власти Мурманской области в качестве инициатора проекта могут выступать любые юридические и физические лица, заинтересованные в результатах реализации предлагаемых проектов.

Определив реализацию проектного подхода и инновационного управления, как одновременную и целесообразную в Арктическом регионе, можно сделать вывод о том, что в системе эффективного развития образовательной среды Мурманской области, на устойчивость внедрения проектного подхода в различных средовых условиях, под которыми понимаются социально-экономические, экологические и технологические условия среды, влияет соотнесение субъектов среды с конкретными участниками и итогами проектной деятельности, реализуемой в практике образовательной деятельности.

Так, за несколько лет реализации системной проектной деятельности в ряде ВУЗов на территории Мурманской области и г. Мурманска, количество участников авторского проекта «Наши 9 шагов к 100-летию» достаточно возросло (2013 г. - 2016 г.: 2 автора-руководителя проекта (Уткова М.А., Утков П.Ю.), 5 участников $[11,12]-$ ежегодная реализация регионального конкурса, 535 участников всех мероприятий под руководством 2 организаторов-членов оргкомитета и научных руководителей проекта, 14 научных руководителей, 8 человек из состава оргкомитета). За период 2016-2018 гг. в системе реализации проектной конкурсной деятельности в условиях реформы образовательного пространства региона, создания и развития деятельности опорного вуза (ФГБОУ ВО «Мурманский арктический государственный университет» - ФГБОУ ВО «МАГУ»), создания Проектного офиса ФГБОУ ВО «МАГУ» и реализации проектной деятельности в вузе, в части руководителей и участников реализации проекта произошел ряд изменений (1 автор-руководитель проекта (Уткова М.А.), 3 человека в составе организационного комитета и членов жюри конкурса, 36 участников проекта-конкурса «Развитие системы волонтерства и добровольчества в прогнозировании и планировании социально-экономических процессов в Арктике» в 2017 году [13], привлечение к соорганизации проведения проектной деятельности Мурманской областной молодежной общественной экологической организации (МОМОЭО) «Природа и молодежь», успешное подведение итогов проекта-конкурса в рамках круглого стола, а также запланированная реализация ежегодного внутривузовского регионального проекта-конкурса «Актуальные направления устойчивого развития экономики Арктического региона», его старт в октябре 2018 года и планируемое подведение итогов на круглом столе в марте 2019 года, а также отличная новость для всех участников - учет результатов проекта-конкурса (при наличии диплома победителя или призера за 2017, 2018, 2019 учебные года) при поступлении на программы бакалавриата и специалитета. Можно подчеркнуть, что проектная деятельность, осуществляемая в условиях реформы образовательной среды в Мурманской области в период с 2013-2019 гг., способствовала устойчивости субъектов образовательной среды, а устойчивость субъектов, в свою очередь, сформировала информационное пространство образовательной среды региона, которое выступало и выступает сегодня системой механиз- 
мов управления реализацией проектной деятельности.

\section{Выводы или заключение}

Таким образом, подводя итоги оценки взаимовлияния проектного управления и устойчивости регионального развития, в системе эколого-экономической безопасности регионального управле- ния к ключевым факторам развития образовательной среды Арктического региона можно отнести социально-экономические, экологические и технологические факторы, а его условия могут быть определены сферой влияния каждого фактора в условиях инвариантного сочетания устойчивости и инновационности развития образования в регионе.

\section{Библиографический список}

1. Добросоцкий В.И. Совершенствование проектного управления в России // Вопросы управления. - 2017. - № 6 (49). - С. 90-97.

2. Раменская Л.А. Особенности проектного управления в органах государственной власти на региональном уровне // Фундаментальные исследования. - 2018. - № 1. - C. 111-115. - URL: http:// fundamental-research.ru/ru/article/view?id=42059 (дата обращения: 02.02.2019).

3. Передовой опыт внедрения проектного управления в органах власти Приморского края. URL: https://blog.pmpractice.ru/2018/01/10/peredovoj-opyt-vnedreniya-proektnogo/ (дата обращения 02.02.2019).

4. Индекс проектной деятельности. Предварительные итоги оценки. - Федеральный проектный офис. Центр проектного менеджмента. - URL: https://pm.center/company/news/predvaritelnye-itogiotsenki-indeksa-proektnoy-deyatelnosti-po-regionam-predstavili-na-krasnoyarskom/ (дата обращения 02.02.2019).

5. Проектный подход в государственном управлении - МФФ 2018. - URL: http:/sovnet.ru/about/ news-blog/3714/ (дата обращения: 02.02.2019).

6. Министерство экономического развития Мурманской области. - URL: https://minec.govmurman.ru/activities/project management/reg projects/ (дата обращения 02.02.2019).

7. Губернатор Мурманской области Марина Ковтун провела Совет по проектной деятельности в Заполярье. - URL: https://blog.pmpractice.ru/2017/12/25/gubernator-murmanskoj-oblasti-marin/ (дата обращения 02.02.2019).

8. Бакланова Ю.О. Эволюция подхода к проектному управлению инновациями: инициатива, проект, программа, портфель // Современные технологии управления. - 2012. - № 3 (15). - URL: https://sovman.ru/article/1501/] (дата обращения 02.02.2019).

9. Официальный сайт Губернатора Мурманской области. - URL: https://gubernator51.ru/aktualno/ fornews/?newsid=277386\&PAGEN_NUM=2\&PAGEN_2=5 (дата обращения 02.02.2019).

10. Васин Н.С., Рябых К.С. Инновационность и устойчивость: проблемы комплементарности // Экономический анализ: теория и практика. - 2014. - № 11 (352). - С. 23-28.

11. Уткова М.А., Утков П.Ю. Эколого-экономическая безопасность в системе регионального управления. - СПб.: СПбУУЭ, 2014. - 116 с.

12. Уткова М.А. Актуализация творческой самоорганизации гуманитарных знаний в развитии региона / Сборник научных статей. Креативные индустрии Арктического региона: опыт и перспективы развития: материалы международного форума 30.11.-01.12.17 г. / отв. ред. Т.В. Ашутова. - Мурманск: МАГУ, 2018. Арктический дизайн: материалы Всероссийской НПК с международным участием 08-10.11.16 г. / отв. ред. Т.В. Ашутова. - Мурманск: МАГУ, Бизнес-пресс, 2018. - С. 131-136.

13. Уткова М.А. Развитие системы волонтерства и добровольчества в управлении социальноэкономическими процессами в Арктике / Современное общество: глобальные и региональные процессы: Материалы V Международной научно-практической конференции 08 февраля 2018 года / Автономная некоммерческая организация высшего образования Московский гуманитарно-экономический университет, Северо-Западный институт (филиал); [редакционная коллегия: Сахневич Т.А. и др.]. - Мурманск: МГЭУ, 2018. - С. 280-285. 